\title{
PERSPECTIVE
}

\section{Management of inherited outer retinal dystrophies: present and future}

\author{
N H Victor Chong, Alan C Bird
}

The inherited outer retinal dystrophies comprise a large number of disorders characterised by a slow and progressive retinal degeneration. They have been arbitrarily divided into macular dystrophies, retinitis pigmentosa (RP), and cone/rod dystrophies on the basis of their phenotype. They are the result of mutations in genes that are presumed to express in either the photoreceptor cells or the retinal pigment epithelium. ${ }^{1}$ Retinitis pigmentosa is believed to affect about one in 3500 of the population, ${ }^{2}$ and the prevalence of remaining dystrophies is probably similar. The mode of inheritance can be autosomal dominant, autosomal recessive, $\mathrm{X}$ linked recessive, ${ }^{3}$ or digenic. ${ }^{4}{ }^{5}$

With few exceptions such as $\alpha, \beta$ lipoproteinaemia ${ }^{67}$ and Refsum disease, ${ }^{8}$ there is no treatment by which the primary disorder can be modified. Some symptomatic relief may be derived from cataract extraction, ${ }^{9}$ and carbonic anhydrase inhibition if there is macular oedema. ${ }^{10}$ Vitamin A supplementation may slow the progression although this has been the subject of controversy. ${ }^{11}{ }^{12}$ Although there is no treatment by which the primary disorder can be manipulated, the patients can expect a reasonable account of visual prognosis, accurate genetic counselling, and support for rehabilitation. In addition, those affected are also keen to know the progress in research for a cure particularly as they have become progressively more aware of the potential for treatment through the various self help associations such as the British Retinitis Pigmentosa Society, the internet, and the press.

Researchers around the world are working on different potential therapeutic approaches to the problem. These are based on the possibility of modulation of cell death by growth factors, transfecting the photoreceptor or retinal pigment epithelial cell with functioning genes, transplanting photoreceptor or retinal pigment epithelial cells into the subretinal space, or the use of electronic devices to stimulate the retina.

\section{Apoptosis and its manipulation}

In some disorders in both humans and animals there is increasing evidence that the metabolic defect consequent upon the mutation causes cell death by apoptosis. This accounts for cone loss in patients with RP due to rhodopsin mutation. ${ }^{13}$ This is also illustrated by loss of photoreceptors in the RCS (Royal College of Surgeons) rat in which the primary defect is in the retinal pigment epithelium. ${ }^{14}$

Apoptosis, or programmed cell death, is a genetically encoded potential of all cells, and is an essential part of embryonic development, cell turnover, and of removal of cells infected by virus or harbouring mutations. ${ }^{15} 16$ Morphologically, it is characterised by disintegration of the nucleolus and generalised condensation of the chromatin. This is due to incision of nuclear DNA by an endogenous nuclease into short chains in multiples of 180 base pairs. In contrast with necrosis the process affects isolated cells with healthy neighbouring cells and in the absence of acute inflammation.

The observation that apoptosis may be manipulated by growth factors suggested an alternative therapeutic approach. The first indication that this may be viable was the demonstration that injection of basic fibroblast growth factor (bFGF) into the eye resulted in long term survival of photoreceptors in the RCS rat. ${ }^{17}$ A potential disadvantage of bFGF is its lack of specificity since it influences many cell types. For instance, in the rabbit it can cause cataract and proliferative vitreoretinopathy. ${ }^{18}$ Neurotrophins, including brain derived neurotrophic factor (BDNF), nerve growth factor (NGF), and neurotrophin 4/5 (NT4/5) appear to be more attractive since they have a relatively specific influence on neural tissue. ${ }^{19}$ They are present in the CNS, and play important roles in neural development, differentiation, and survival. ${ }^{19}$ Another important neurotrophic factor is the ciliary neurotrophic factor (CNTF) which is closely related to interleukin $6 .{ }^{20}$ There is an increasing body of experimental work that illustrates the potential value of this approach. Intravitreal injections of $\mathrm{BDNF}, \mathrm{CNTF}$, or bFGF transiently protect the retina from pressure induced ischaemic injury. ${ }^{21}$ Both BDNF and CNTF protect the retina from light damage in albino rats and mice. ${ }^{22}{ }^{23} \mathrm{BDNF}$ also promotes the regrowth of outer segments of photoreceptors in a feline retinal detachment model. ${ }^{24} \mathrm{CNTF}$ delays photoreceptor degeneration in $\mathrm{rd}$ (retinal degeneration) mice, ${ }^{23}$ transgenic rhodopsin Q344ter mutant mice, ${ }^{23}$ and Rdy (retinal dystrophy) cats. $^{25}$

This form of treatment of retinal degeneration has the advantage that it may be effective in disease with unknown genetic mutation. It is unfortunate that the effect of the neurotrophic factors is relatively short lived, lasting only about a month in animals ${ }^{22} 23$ although the effect may be much longer in humans. Repeated monthly intravitreal injections would present ergonomic difficulties, and inevitably be accompanied by attendant risks such as retinal detachment and endophthalmitis. Biological and biochemical slow delivery systems are being developed that may overcome these problems. ${ }^{26}$

\section{Gene therapy}

In most recessive and some dominant diseases, cell dysfunction is due to lack of functioning genes, and the objective of therapy is the replacement of the defective gene with genes that express normally.

In the retinal degeneration slow (rds) mice, transfection of the fertilised ovum with the appropriate wild type (normal) gene results in photoreceptor cell rescue. ${ }^{27}$ However, insertion of genes into non-dividing photoreceptor cells in human is a much greater challenge. There are two general approaches by which genes can be introduced into the eye, 
ex vivo or in vivo. In the ex vivo techniques, the genes are introduced in vitro into retinal cells, retinal pigment epithelial (RPE) cells, or fibroblasts. The transfected cells are then injected into the eye. In vivo, or direct gene transfer, genes are introduced into the cells in situ using a vector. The most commonly used gene vectors are the replication defective herpes simplex virus, the replication defective adenovirus, adeno-associated virus (AAV), and retrovirus. Each has advantages and disadvantages.

Herpes virus can carry a large gene insert (up to $36 \mathrm{~kb}$ ). However, it rapidly undergoes latency after infection restricting the long term expression of the transgenes. This drawback can be overcome by using one of the latency promoters as the helper for transgene expression so it remains active in latency. A cytotoxic response may occur in the target cells that would reduce the longevity of expression. ${ }^{28}$ Furthermore, the wild type herpes virus carries a significant morbidity in humans. The adenovirus is a relatively safe virus. However, it induces an immune response that prevents reinfection by the same virus, and cytotoxic effect on the target cells reducing expression longevity. ${ }^{29}$ The current capacity for a gene insert is relatively small (about $8 \mathrm{~kb}$ ), but with development of new packaging cell lines, a larger insert might be achieved. However, transfection efficiency in general is low in that only a small proportion of cells are transfected and expression is brief. The AAV is an attractive alternative as it is not associated with any pathological response in humans. The recombinant $A A V$ vectors have no virally encoded proteins and hence less immunogenicity. They can infect a variety of cells, and are more efficient in transducing photoreceptors than adenovirus. Wild type AAV integrates into chromosome 19, while recombinant AAV may integrate randomly. The latter has the potential risk of disrupting essential genes or causing malignant transformation of the target cells, although there is little evidence of this to date. Chromosomal integration may serve to prolong expression. The maximum size of insert is only $4.7 \mathrm{~kb}$, and it is difficult to prepare high titres without contamination of helper adenovirus. ${ }^{29}$ Retrovirus can only infect dividing cells, which restricts its use in the retina.

The most promising observation to date is the reported delay of photoreceptor cell death in the rd mice (b-PDE defect) by the use of subretinal injection of a recombinant replication defective adenovirus that contains the murine cDNA for the wide type b-PDE. It is reported that these injections result in b-PDE transcription, and increased PDE activity, although the rescue only lasted for 6 weeks. ${ }^{30}$ In all these observations, there must always be doubt as to whether the therapeutic effect is due to the expression of the gene or to injury with the attendant release of growth factors or the immune response to the viral vectors.

On the other hand, in most dominant diseases it is likely that the abnormal gene product produces disease. An antisense protein would be required to negate the influence of the abnormal gene. However, antisense molecules are often too big to discriminate wild type and mutant mRNA in point mutation, as seen in much autosomal dominant RP. ${ }^{131}$ Recently, ribozymes present new promises. They can bind and digest targeted mRNA. Specifically designed ribozymes can discriminate between the mutant and wild type sequences of mRNA associated with autosomal dominant RP. ${ }^{31}$ Furthermore, using an AAV vector, ribozymes rescue photoreceptor cells in the transgenic rhodopsin P23H mutant rats. ${ }^{32}$

Gene therapy could also be used to deliver neurotrophic factor. ${ }^{33}$ These approaches can also be combined by reintroduction of genetic modified host cells expressing the neurotrophic factors. The longevity of expression remains the problem, but with ex vivo transfection there is a wide scope for manipulation of expression.

\section{Retinal cell transplantation}

The ultimate goal of transplantation is to replace lost photoreceptors with healthy ones, which would have the capacity to re-establish the appropriate cellular connections at the outer plexiform layer. Cell survival appears to be related to donor age. Transplanted fetal tissue appears to survive and differentiate, but fails to show normal orientation in the retina. ${ }^{34}$ Enzymatic dissociated adult photoreceptor cells can be transplanted by injection into the subretinal space. Such photoreceptors survive and appear to have synaptic terminals but their outer segments degenerate almost completely. ${ }^{35}{ }^{36}$ However, the functional attributes of these cells have not been tested since the visually directed behaviour of these animals was not assessed. There is also some evidence to suggest that cones survived longer following transplantation in the $\mathrm{rd}$ mouse. ${ }^{37}$ This might reflect the influence of trophic factors.

Despite the paucity of evidence that this technique may be useful, mechanically dissociated fetal retina of 14-18 weeks' gestation have been grafted in 12 patients with advanced RP. The preoperative visual acuity was perception of light or worse. No rejection or complications were reported. Five patients had reported subjective improvement of vision. ${ }^{38}$ However, it is impossible to exclude the placebo effect or the influence of injury. Furthermore, no improvement of vision was found in two patients transplanted with a sheet of adult photoreceptors harvested by vibratome. ${ }^{39}$

Another strategy is the transplantation of RPE cells. In the RCS rat, the RPE failed to phagocytose photoreceptor outer segment material. This accumulation of outer segment material results in photoreceptor cell death. ${ }^{14}$ Transplantation of healthy RPE cells into subretinal space delayed photoreceptor loss and retinal function, as measured by electroretinogram and pupillary light reflex, is restored following RPE cell grafts in the RCS rats. ${ }^{40-43}$ However, this may have limited relevance to most human forms of retinal dystrophy, although it may have a role in slowing the progress of age related macular degeneration. The results of human fetal RPE transplantation in 13 patients with age related macular degeneration were recently reported. ${ }^{44}$ No visual improvement was observed but the graft was reported to survive in most of the patients.

\section{Artificial vision}

It is well known that stimulation of the appropriate area of the visual cortex causes a visual sensation. Some scientists are working on devices that can detect visual signals, and stimulate the visual cortex directly. Thus, no viable eye tissue are required, but the signal bypasses the sophisticated coding of the visual system, and the sensations are likely to be complex depending upon the functional attributes of the cell stimulated. This renders the potential success of this approach problematic.

There has been extensive media coverage of the artificial retinal implant for blind people. The concept is based on the fact that in RP, the photoreceptors are damaged but the inner retina remains relatively healthy. Electrical stimulation of the inner surface of rabbit retina was the first demonstration of the possibilities of retinal implants. ${ }^{45}$ These experiments were later carried out in humans. Subsequently, intraocular electrodes coupled with an optically isolated, constant current generator were used to deliver the pulses. This was performed in five patients with bare or no perception of light (three had RP, one had age related macular degeneration, and one unspecified retinal 
dystrophy from birth). Stimulation elicited a visual perception of a spot that was retinotopically correct in four subjects who had had previously useful vision. One subject resolved two simultaneous spots giving a visual acuity of about $1 / 60 .^{46}$ However, the methods for permanent implantation of such devices, and their connection with the outside world may pose major technical problems. Furthermore, the number of stimulating electrodes and the visual field covered are likely to be very limited. Even if these problems are resolved, it is unlikely to simulate foveal function without the presence of photoreceptors.

\section{Conclusion}

We are still a long way from the cure of retinitis pigmentosa, although it is encouraging to the patients and their carers that there is a worldwide effort to devise new methods of management. Although none of the techniques appear to be very effective for long term modification of the course of the disorder, the vast majority of retinal dystrophies are slowly progressive, and many patients retain good visual function for a large part of their lives. A small change in the metabolic environment of the retina may have a great influence on the dynamics of the degeneration.

In the short term (5-10 years), the use of growth factor is possibly the most promising approach, although in the long term it may not be the best solution. Transplantation might be useful to preserve central vision while the artificial retinal implant might be useful to maintain visual field. Gene therapy might ultimately be the best treatment, but currently it is an immature genie yet to deliver its promises.

NHVC is supported by an MRC clinical training fellowship.

\section{N H VICTOR CHONG}

ALAN C BIRD

Institute of Ophthalmology (UCL), Moorfields Eye Hospital, City Road, London EC1V 2PD

Correspondence to: Mr Victor Chong, Professorial Unit, Moorfields Eye Hospital, City Road, London EC1V 2PD.

1 Bird AC. Retinal photoreceptor dystrophies. Am f Ophthalmol 1995; 119:543-62

2 Bunker CH, Berson EL, Bromley WC, et al. Prevalence of retinitis pigmentosa in Maine. Am f Ophthalmol 1984;97:357-65.

3 Jay $M$. On the heredity of retinitis pigmentosa. $\mathrm{Br} \mathcal{F}$ Ophthalmol 1982;66:405-16.

4 Goldberg AF, Molday RS. Defective subunit assembly underlies a digenic form of retinitis pigmentosa linked to mutations in peripherin/rds and rom-1. Proc Natl Acad Sci USA 1996;93:13726-30.

5 Kajiwara K, Berson EL, Dryja TP. Digenic retinitis pigmentosa due to mutations at the unlinked peripherin/RDS and ROM1 loci. Science 1994;264:1604-8

6 Illingworth DR, Connor WE, Miller RG. $\alpha$-Betalipoproteinemia: report of two cases and review of therapy. Arch Neurol 1980;37:659-62.

7 Gouras P, Carr RE, Gunkel RD. Retinitis pigmentosa in $\alpha$-betalipoproteinemia: effects of vitamin A. Invest Ophthalmol 1971;10:784-93.

8 Hansen E, Bachen NI, Flage T. Refsum's disease. Eye manifestations in a patient treated with low phytol low phytanic acid diet. Acta Ophthalmol patient treated with

9 Newsome DA, Stark-WJ J, Maumenee IH. Cataract extraction and intraocular lens implantation in patients with retinitis pigmentosa or

10 Cox SN, Hay E, Bird AC. Treatment of chronic macular oedema with acetazolamide. Arch Ophthalmol 1988;106:1190-5.

11 Berson EL, Rosner B, Sandberg MA, et al. A randomized trial of vitamin A and vitamin E supplementation for retinitis pigmentosa. Arch Ophthalmol 1993;111:761-72.

12 Massof RW, Finkelstein D. Supplemental vitamin A retards loss of ERG amplitude in retinitis pigmentosa. Arch Ophthalmol 1993;111:751-4.

$13 \mathrm{Gal}$ A, Apfelstedt Sylla E, Janecke AR, et al. Rhodopsin mutations in inherited retinal dystrophies and dysfunctions. Prog Ret Eye Res 1997;16:51-79.
14 Mullen RJ, LaVail MM. Inherited retinal dystrophy: primary defect in pigment epithelium determined with experimental rat chimeras. Science 1976; 192:799-901.

15 Wyllie AH, Kerr JFR, Currie AR. Cell death: the significance of apoptosis. Int Rev Cytol 1980;68:251-306.

16 Raff MC, Barres BA, Burne JF, et al. Programmed cell death and the control of cell survival. Philos Trans R Soc Lond B Biol Sci 1994;345:265-8.

17 Faktorovich EG, Steinberg RH, Yasumura D, et al. Photoreceptor degeneration in inherited retinal dystrophy delayed by basic fibroblast growth factor. Nature 1990;347:83-6.

18 Borhani H, Peyman GA, Rahimy MH, et al. Vitreoretinal toxicity of basic fibroblast growth factor. Int Ophthalmol 1993;17:195-9.

19 Thoenen H. The changing scene of neurotrophic factors. Trends Neurosci 1991;14:165-70.

20 Richardson PM. Ciliary neurotrophic factor: a review. Pharmacol Ther 1994; 63:187-98.

21 Unoki K, LaVail MM. Protection of the rat retina from ischemic injury by brain-derived neurotrophic factor, ciliary neurotrophic factor, and basic fibroblast growth factor. Invest Ophthalmol Vis Sci 1994;35:907-15.

22 LaVail MM, Unoki K, Yasumura D, et al. Multiple growth factors, cytokines, and neurotrophins rescue photoreceptors from the damaging effects of constant light. Proc Natl Acad Sci USA 1992;89:11249-53.

23 LaVail MM, Yasumura D, Matthes MT, et al. Protection of mouse photoreceptors by survival factors in retinal degenerations. Invest Ophthalmol Vis Sci 1998;39:592-602

24 Fisher SK, Guerin CJ, Linberg KA, et al. BDNF promotes outer segment regeneration in experimentally detached retina. Invest Ophthalmol Vis Sci (Suppl) 1995;36:963.

25 Chong NHV, Alexander RA, Waters L, et al. CNTF analogue, but not $\mathrm{BDNF}$, delays photoreceptor cell death in retinal degeneration. Invest $O p h$ thalmol Vis Sci (Suppl) 1998;39:2689

26 Maysinger D, Krieglstein K, FilipovicGrcic J, et al. Microencapsulated ciliary neurotrophic factor: physical properties and biological activities. Exp Neurol 1996;138:177-88.

27 Travis GH, Groshan KR, Lloyd M, et al. Complete rescue of photoreceptor dysplasia and degeneration in transgenic retinal degeneration slow (rds) mice. Neuron 1992;9:113-9.

28 Pepose JS, Leib DA. Herpes simplex viral vectors for therapeutic gene delivery to ocular tissues. Recent breakthroughs in the molecular genetics of ocular diseases. Invest Ophthalmol Vis Sci 1994;35:2662-6.

29 Ali RR, Reichel MB, Hunt DM, et al. Gene therapy for inherited retinal degeneration. Br f Ophthalmol 1997;81:795-801.

30 Bennett J, Tanabe T, Sun D, et al. Photoreceptor cell rescue in retinal degeneration (rd) mice by in vivo gene therapy. Nature Med 1996;2:649 54

31 Dreunser KA, Timmers AM, Hauswirth WW, et al. Ribozyme-targeted destruction of RNA associated with autosomal-dominant retinitis pigmentosa. Invest Ophthalmol Vis Sci 1998;39:681-9.

32 Lewin AS, Hauswirth WW, Drenser K, et al. Ribozyme rescue of photoreceptor cells in a transgenic rat model of autosomal dominant retinitis pigmentosa. Invest Ophthalmol Vis Sci (Suppl) 1998;39:5150.

33 Cayouette M, Gravel C. Adenovirus-mediated gene transfer of ciliary neurotrophic factor can prevent photoreceptor degeneration in the retinal degeneration (rd) mouse. Hum Gene Ther 1997;8:423-30.

34 Aramant RB, Seiler MJ, Turner JE. Donor age influences on the success of retinal transplants to adult rat retina. Invest Ophthalmol Vis Sci 1988; 29:498-503

35 Gouras P, Du J, Gelanze M, et al. Survival and synapse formation of transplanted rat rods. F Neural Transplant Plast 1991;2:91-100.

36 Gouras P, Du J, Gelanze M, et al. Transplantation of photoreceptors labelled with tritiated thymidine into RCS rats. Invest Ophthalmol Vis Sci 1991;32:1704-7.

37 Mohand-Said S, Hicks D, Simonutti M, et al. Photoreceptor transplants increase host cone survival in the retinal degeneration (rd) mouse. Ophthalmic Res 1997;29:290-7.

38 del Cerro M, Das TP, Lazar ES, et al. Neural retinal transplantation into twelve RP patients. Invest Ophthalmol Vis Sci (Suppl) 1997;38:1204.

39 Kaplan HJ, Tezel TH, Berger AS, et al. Human photoreceptor transplantation in retinitis pigmentosa. A safety study. Arch Ophthalmol 1997;115: 1168-72

40 Sheedlo HJ, Li LX, Turner JE. Functional and structural characteristics of photoreceptor cells rescued in RPE-cell grafted retinas of RCS dystrophic rats. Exp Eye Res 1989;48:841-54.

41 Sheedlo HJ, Li LX, Turner JE. Photoreceptor cell rescue in the RCS rat by RPE transplantation: a therapeutic approach in a model of inherited retinal dystrophy. Prog Clin Bio Res 1989;314: 645-58.

42 Whiteley SJ, Litchfield TM, Coffey PJ, et al. Improvement of the pupillary light reflex of Royal College of Surgeons rats following RPE cell grafts. Exp Neurol 1996;140:100-4.

43 Yamamoto S, Du J, Gouras P, et al. Retinal pigment epithelial transplants and retinal function in RCS rats. Invest Ophthalmol Vis Sci 1993;34:3068 75.

44 Algvere PV, Berglin L, Gouras P, et al. Transplantation of RPE in age-related macular degeneration: observations in disciform lesions and dry RPE atrophy. Graefes Arch Clin Exp Ophthalmol 1997;235:149-58.

45 Humayun MS, Propst R, de Juan E Jr, et al. Bipolar surface electrical stimulation of the vertebrate retina. Arch Ophthalmol 1994;112:110-6.

46 Humayun MS, de Juan E Jr, Dagnelie G, et al. Artificial vision. Invest Ophthalmol Vis Sci (Suppl) 1996;37:2055. 